\title{
The corrosion of stirrups and its effect on the seismic fragility of a corroded reinforced concrete column
}

\author{
G. Zhang \& B. Li \\ Nanyang Technological University, Singapore
}

\begin{abstract}
As service rates increase, the corroded rebar stands out as a major problem for existing reinforced concrete (RC) columns in a corrosion-inducing environment. The corrosion of stirrups is more serious than that of longitudinal bars, due to smaller clear concrete cover and smaller diameter. It deteriorates the confinement behaviour and thus decreases the shear resistant capacity, potentially changing the failure modes from ductile flexural failure mode to brittle flexural-shear failure mode, or even shear failure mode. Therefore, the evolution of the seismic damage pattern of existing corroded RC columns and its service-year related fragility analysis are becoming heated research topics in the field of structure hazard prevention research. The objectives of this paper will be to focus on how to use FEM software to numerically simulate the seismic behaviour of corroded columns accounting for materials deterioration and bond degradation. Pushover curves shown that a transverse rebar corrosion level above $10 \%$ could reduce the seismic capacity of columns by a great extent. In addition, the stiffness, ductility and energy dissipation capacity declines. It also demonstrated the transition of failure mode from flexure failure to shear failure as the corrosion level of stirrups increased. The fragility analysis based on the FEM results indicated that the RC column with corroded stirrups is much more vulnerable.

Keywords: stirrup corrosion, bond degradation, seismic fragility analysis, FEM, damage pattern, brittle failure.
\end{abstract}

\section{Introduction}

The corrosion of reinforcement steel bars (rebar) is a natural electrochemical reaction reinforced concrete $(\mathrm{RC})$ structures have to be faced with. It is exacerbated by exposure to corrosion-inducing environment factors, including 
de-icing salt, marine salty water, carbon dioxide and sulphur dioxide, among others. The chloride from salt $(\mathrm{NaCl})$ could make hazardously chemical attack on a steel bar by acting as an efficient catalyst in the corrosion process. The corrosion of steel bars in an existing reinforced concrete structure has raised great concerns over its safety and seismic performance among practising engineers, researchers and residents, because a steel bar is the most essential element in RC. Corrosion reduces the effective cross-section area of longitudinal and transverse rebars. As shown in Fig. 1, the volume expansion of the corrosion product will give rise to cover cracking, as a result of which effective concrete area could be reduced.
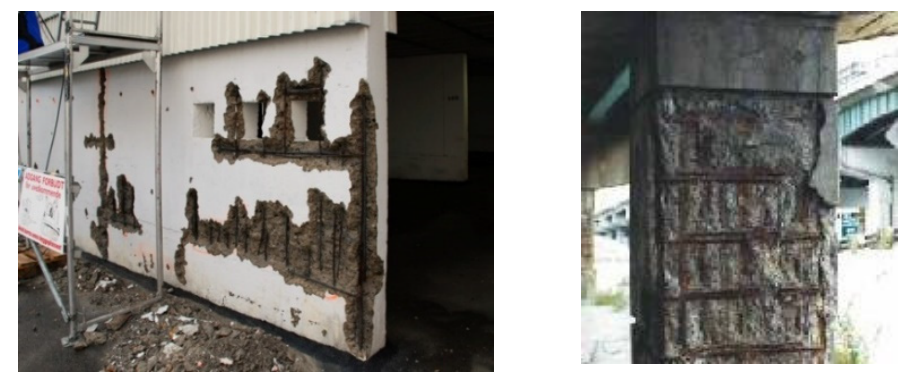

Figure 1: Corrosion of transverse rebars.

Furthermore, the interaction between concrete and steel bars could be changed fundamentally as the steel bars have an increasing corrosion level. In the primary phase, the expansion of the corrosion products enhances the confinement behaviour of the concrete towards the rebar. Moreover, the particle of corrosion products raises the friction coefficient, which is more obvious for smooth bars. Both described factors contribute to the increase of bond strength in the primary phase. But as more corrosion products accumulate, the chemical cohesion will deteriorate. It may even lead to the reduction of the friction coefficient. For a deformed bar, the ribs could be eradicated, which reduces the mechanical interlocking. Also, the expansion effect of the corrosion products can lead to the cracking of the concrete cover, adversely resulting in the decrease of the confinement. Thus, the bond strength declines as the corrosion level exceeds the boundary value (generally this is $5 \%$ ).

In experimental studies and engineering investigations on corroded $\mathrm{RC}$, many scholars including Li and Yang [1], Ma et al. [2] and Wang and Liang [3] found that the transverse rebar could undergo more severe damage than the longitudinal rebar, and even break at the junction point with the longitudinal rebar. Because of the comparative smaller depth of concrete cover for transverse rebars, the latter are more easily reached by chloride and other corrosion induction chemicals. Besides, the diameter of transverse rebars is smaller than that of the longitudinal reinforcement so transverse reinforcement is more vulnerable to corrosion, especially that at the corner of the column. So, transverse rebar corrosion turns out to start earlier and have higher levels than that of longitudinal rebars.

The corrosion of transverse rebars will seriously degrade the confinement behaviour and thus reduce the shear resistance of the column. Consequently, 
the damage mode could be shifted from ductile bending failure to brittle bending-shear failure or shear failure. However, up until now, experimental studies and numerical modelling have focused on how corroded longitudinal rebars affect the seismic performance and fragility of an RC beam in general and the corrosion level of transverse rebars has been underestimated. Uncertainties remain on how severely corroded transverse rebars will affect the mechanical strength, seismic capacity and seismic fragility of an RC element column.

Therefore, this contribution will firstly discuss the use of nonlinear finite element analysis (NLFEA) software Abaqus to simulate the behaviour of a corroded RC structure, especially focusing on how to model corrosion-induced cracked concrete, corroded steel rebar, and the bond strength between concrete and rebar, among others. Then, based on these techniques, this paper will present a parametric study on how a highly corroded transverse rebar affects the seismic behaviour of an RC circular column, as well as fragility curves using nonlinear pushover analysis.

\section{Methodology for modelling corroded RC}

The high nonlinearity of corroded RC structures can be attributed to corrosioninduced cracks in cover concrete, deteriorated steel bar and degraded bond strength between concrete and rebar. Ou et al. [4], Sæther and Sand [5] and many other investigators have looked into how corroded RC can be numerically simulated with various finite element analysis software and different approaches. This study utilizes the widely available nonlinear finite element modelling software Abaqus version 6.10.1, which enjoys a great reputation for handling problems with extensive plasticity using a smart solver with automatic increment [6]. This section will explain the challenges in modelling corroded RC and the methods adopted to meet them using Abaqus.

\subsection{Cover concrete with corrosion-induced cracking}

Bazant [7], Liu and Weyers [8], and $\mathrm{Vu}$ et al. [9] conducted analytical and numerical studies on how corrosion-induced cracking could be modelled. These approaches are mostly based on the closed-from assumption. According to this assumption, corrosion products replace the concrete-steel interface. The expansion of corrosion products results in the evolution of circumferential stress in the surrounding concrete. The concrete cracking occurs when the circumferential stress exceeds the tensile strength. Different kinds of modification factors were proposed to account for the stiffness degradation of the cracked concrete. Ou et al. [4] proposed a softening effect coefficient to account for the softening effect of cracking concrete, as follows:

$$
\zeta=\frac{0.9}{\sqrt{1+600 \varepsilon_{r}}}
$$

where $\varepsilon_{r}$ is the tensile strain of the cover concrete. The stress strain curve of cracked cover concrete could be expressed as: 


$$
\sigma=\left\{\begin{array}{c}
\zeta f_{c}^{\prime}\left[2\left(\frac{\varepsilon}{\zeta \varepsilon_{0}}\right)-\left(\frac{\varepsilon}{\zeta \varepsilon_{0}}\right)^{2}\right] \quad \varepsilon<\zeta \varepsilon_{0} \\
\zeta f_{c}^{\prime}\left[1-\left(\frac{\frac{\varepsilon}{\zeta \varepsilon_{0}}-1}{\frac{2}{\zeta}-1}\right)^{2}\right] \\
\varepsilon \geq \zeta \varepsilon_{0}
\end{array}\right.
$$

where $\varepsilon_{0}$ is the concrete strain corresponding to the concrete peak stress.

Abaqus has two different material models for concrete: one is damaged plasticity; the other is smeared cracking [6]. Both could describe the stress strain curve by specifying the data points. Damaged plasticity is used in the present modelling of cracked concrete, because it is superior to smeared cracking in terms of convergence rate. As has been described above, softened cover concrete caused by corrosion cracking is simulated by introducing softening factors and modified the concrete stress strain curve.

\subsection{Geometry and material strength of corroded rebar}

Corrosion initially damages the rebar by eating away steel and reducing the cross section. In experimental studies, the corrosion level is generally measured as the percentage of decreased bar weight relative to the prime bar weight $[2,10]$. However, this method fails to describe the true corrosion status by ignoring the position, the depth and area of corrosion pit. This rough way of calculating rebar corrosion level could be idealized as uniform cross section reduction. Even though corrosion is localized and non-uniform by nature, this method has been shown to represent the geometry change of rebar and yielded good modelling results. Lee et al. [11] reported that a corroded steel bar has reduced yield and ultimate strength as well as smaller elastic modulus. Regression analysis produced linear equations to calculate the mechanical parameters of a corroded rebar; these are listed in Table 1 where $\Delta c$ is the corrosion level (\%). Fig. 2 shows the reduction factor for each of the parameters of the corroded rebar. Abaqus provides a steel material model with plasticity, explicitly identifying the stress and the corresponding inelastic strain.

Table 1: Mechanical properties of corroded reinforcement.

\begin{tabular}{|l|c|}
\hline Mechanical properties parameters & Equation for mechanical properties \\
\hline Yield strength & $\sigma_{\mathrm{cy}}=(1-1.98(\Delta \mathrm{c} / 100)) \sigma_{y}$ \\
\hline Ultimate strength & $\sigma_{\mathrm{cu}}=(1-1.57(\Delta \mathrm{c} / 100)) \sigma_{u}$ \\
\hline Elastic modulus & $\left.E_{c s}=(1-1.15 \Delta \mathrm{c} / 100)\right) E_{s}$ \\
\hline Elongation & $\delta_{c}=(1-2.59(\Delta \mathrm{c} / 100)) \delta$ \\
\hline
\end{tabular}




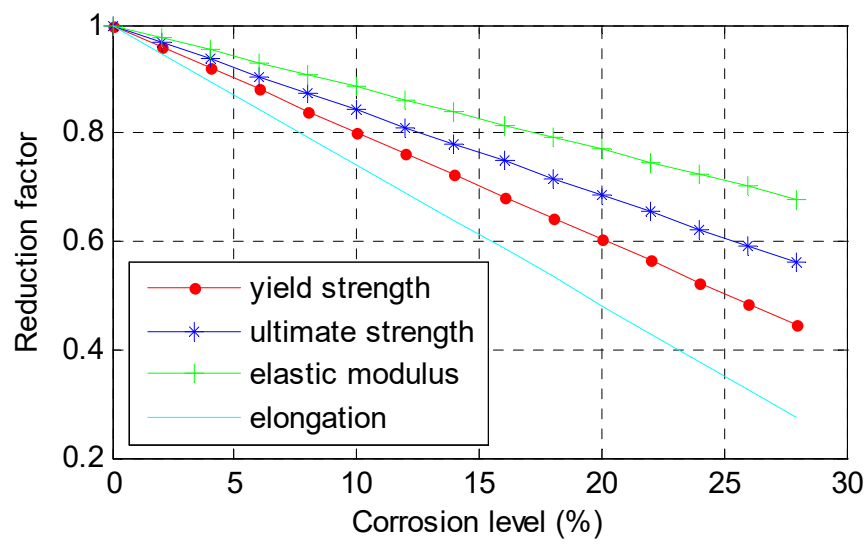

Figure 2: Strength degradation of corroded rebar.

\subsection{Simulate bond strength degradation in Abaqus}

In modelling concrete, the general practice is to model rebars as truss or beam elements and embed them into concrete which is usually discretized as solid element. This approach has been based on the "perfect bond" assumption that concrete is "perfectly" connected to concrete, which would overestimate the capacity of corroded RC structure.

CEB-FIP 1990 [12] provides guidance on the bond-slip value of confined concrete, as shown in Fig. 3 and Table 2; according to which, the bond strength depends on two major conditions - whether the concrete is confined or not and whether the bond is good. In addition, the ascend branch of the model is defined by the equation:

$$
\tau_{b}=\tau_{\max }\left(\frac{s}{s_{1}}\right)^{\alpha} \quad \text { when } s \leq s_{1}
$$

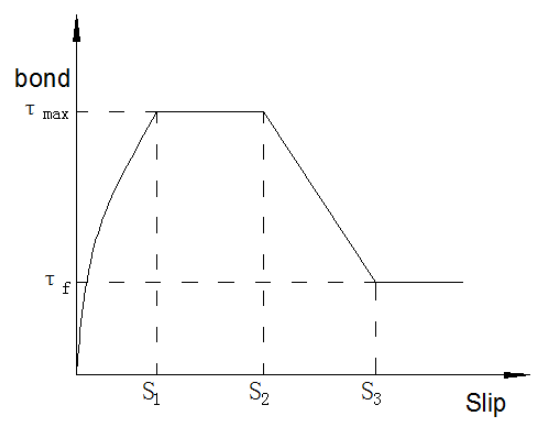

Figure 3: Bond-slip relationship. 
Table 2: Parameters for defining bond-slip value.

\begin{tabular}{|l|c|c|c|c|}
\hline & \multicolumn{2}{|c|}{ Unconfined concrete } & \multicolumn{2}{c|}{ Confined concrete } \\
\hline & $\begin{array}{c}\text { Good bond } \\
\text { condition }\end{array}$ & $\begin{array}{c}\text { All other } \\
\text { bond } \\
\text { conditions }\end{array}$ & $\begin{array}{c}\text { Good bond } \\
\text { condition }\end{array}$ & $\begin{array}{c}\text { All other } \\
\text { bond } \\
\text { conditions }\end{array}$ \\
\hline $\mathrm{S}_{1}(\mathrm{~mm})$ & 0.6 & 0.6 & 1 & 0.6 \\
\hline $\mathrm{S}_{2}(\mathrm{~mm})$ & 0.6 & 0.6 & 3 & 0.6 \\
\hline $\mathrm{S}_{3}(\mathrm{~mm})$ & 1.0 & 1.0 & $\begin{array}{c}\text { Clear rib } \\
\text { spacing }\end{array}$ & $\begin{array}{c}\text { Clear rib } \\
\text { spacing }\end{array}$ \\
\hline$\alpha$ & 0.4 & 0.4 & 0.4 & 0.4 \\
\hline$\tau_{\mathrm{max}}(\mathrm{MPa})$ & $2 \sqrt{f_{c}^{\prime}}$ & $\sqrt{f_{c}^{\prime}}$ & $2.5 \sqrt{f_{c}^{\prime}}$ & $1.25 \sqrt{f_{c}^{\prime}}$ \\
\hline$\tau_{f}(\mathrm{MPa})$ & $0.15 \tau_{\max }$ & $0.15 \tau_{\max }$ & $0.4 \tau_{\max }$ & $0.4 \tau_{\mathrm{max}}$ \\
\hline $\mathrm{S}_{4}(\mathrm{~mm})$ & - & - & $0.5 \mathrm{~S}_{3}$ & $0.5 \mathrm{~S}_{3}$ \\
\hline$\tau_{y}(\mathrm{MPa})$ & - & - & $0.5 \tau_{f}$ & $0.5 \tau_{f}$ \\
\hline
\end{tabular}

$\mathrm{Xu}$ [13] tested the bond strength of accelerated carrion specimen on different corrosion levels and conducted regression analysis on the experiment data; they then proposed a relationship between the bond strength reduction factor and different corrosion levels, as follows:

$$
\beta=\left\{\begin{array}{cc}
1+0.5625 \eta-0.3375 \eta^{2}+0.055625 \eta^{3}-0.003 \eta^{4} & \eta \leq 7 \% \\
2.0786 \eta^{-1.0369} & \eta>7 \%
\end{array}\right.
$$

where $\beta$ is the bond strength reduction factor and $\eta$ the corrosion level.

Abaqus [6] has the functionality to model the bond behaviour between the concrete and reinforcement by defining interaction contact properties with tangential behaviour, normal behaviour and cohesive behaviour. Tangential behaviour could be defined as penalty friction formulation with friction coefficient, shear stress limit, and elastic slip stiffness, among others, which altogether could fully simulate the bond slip behaviour in corroded RC structure.

\section{Numerical study on influence of transverse rebars}

\subsection{Details of modelling specimen}

In order to clarify the influence of corroded transverse rebars on the seismic capacity of RC columns, it is essential to look at transverse rebar corrosion level separately. A RC circular column in the experimental study by Ma et al. [2] was chosen. The circular column has dimensions as shown in Fig. 4, the concrete cylindrical strength is $20.1 \mathrm{MPa}$; the clear cover depth is $30 \mathrm{~mm}$; the yield strength and ultimate strength of longitudinal rebar is $373 \mathrm{MPa}$ and $572 \mathrm{MPa}$, respectively; 
the yield strength and ultimate strength of transverse rebar is $327 \mathrm{MPa}$ and 510 MPa, respectively. As has been discussed, researching on how transverse rebar corrosion affects the seismic capacity holds value in understanding corrosion more thoroughly. In order to achieve this goal, a parametric study was designed with transverse rebar corrosion level, longitudinal rebar corrosion level as the control variables, as listed in Table 3. A set of sixteen samples were created, denoted as LxTy, in which x means corrosion level of longitudinal bar and y means corrosion level of transverse bar.
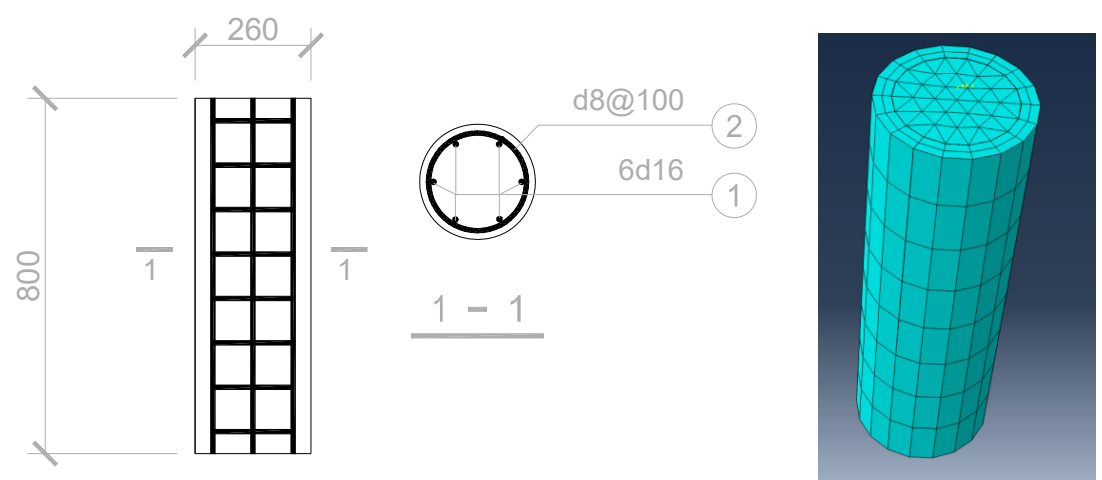

Figure 4: Dimensions of RC circular column, rebar detailing and FEM model (unit: $\mathrm{mm}$ ).

Table 3: Control variables for parametric study.

\begin{tabular}{|c|c|c|c|c|}
\hline$\Delta c_{l}$ & \multicolumn{4}{|c|}{$\Delta c_{t}$} \\
\hline $0 \%$ & $0 \%$ & $5 \%$ & $10 \%$ & $15 \%$ \\
\hline $5 \%$ & $5 \%$ & $10 \%$ & $15 \%$ & $20 \%$ \\
\hline $10 \%$ & $10 \%$ & $15 \%$ & $20 \%$ & $25 \%$ \\
\hline $15 \%$ & $15 \%$ & $20 \%$ & $25 \%$ & $30 \%$ \\
\hline
\end{tabular}

According to Table 3, a total of 16 models were created. As shown in Fig. 4, in the 3D model, concrete is discretized into solid homogenous elements; rebars are modelled using truss elements; the interaction between concrete and a steel bar is simulated by contact properties. The material properties of cracked concrete cover and concrete-rebar contact is introduced in the last section; the truss element section area was reduced according to corrosion level. Also, each element was subject to monotonic pushover analysis. The axial load ratio is 0.15 . The maximum displacement at the top of the column is $50 \mathrm{~mm}$, which makes the drift ratio $6.25 \%$. 


\subsection{Parametric study results}

Reaction force $F_{r}$ and displacement $D$ were retrieved from analysis results, as they could represent the overall seismic capacity. Previous analysis yielded 16 pushover curves, as shown in Figs. 5-7. Specimens with the same longitudinal rebar corrosion level yield at almost the same displacement. In Fig. 5, as the longitudinal corrosion level increases, the columns have smaller maximum strength at smaller displacement. The seismic capacity and elastic behaviour are still controlled by longitudinal bars. Separate investigation reveals that columns with transverse rebar severely damaged tend to have steeper descending branch and the reaction force decreases comparatively faster, which is fully demonstrated by L0T15 and L5T20 in Fig. 6. Columns with high transverse corrosion level apparently sustain more strength loss and ductility loss after yielding because of the sharp reduction of confinement behaviour. As illustrated in Fig. 6, a brittle failure appeared in specimens L0T5 and L5T15, L5T20 in which the longitudinal rebars do not have high corrosion levels. Corrosion of transverse rebar fundamentally changes the failure modes of columns. Fig. 7 shows that as the corrosion level of longitudinal rebars reaches $15 \%$, the differences in the descending branches become minor. As the corrosion level of longitudinal rebars increases, the effect of transverse rebars weakens. As a matter of fact, in the natural corrosion phenomena of RC structures, the corrosion level of longitudinal rebars hardly reaches $15 \%$, while the transverse rebar has a greater probability to suffer from much higher level of corrosion.

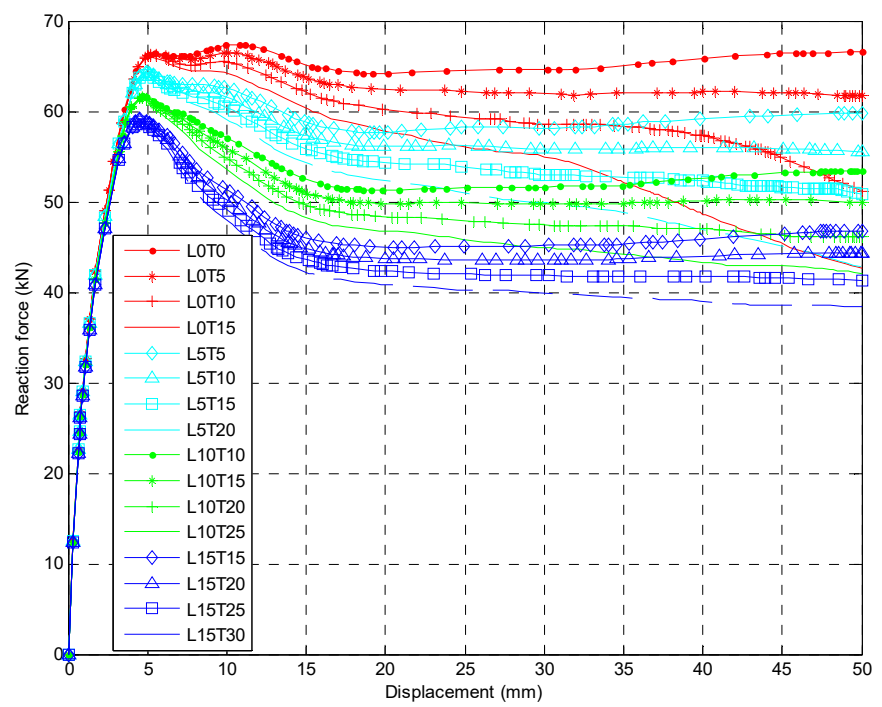

Figure 5: Pushover curves of L0T0-L0T15 and L5T5-L5T20. 


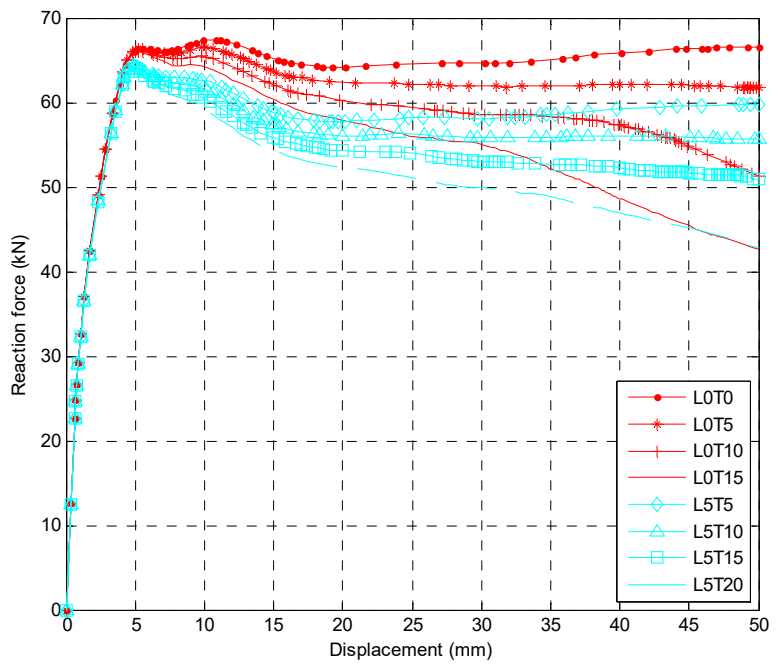

Figure 6: Pushover curves of L0T0-L0T15 and L5T5-L5T20.

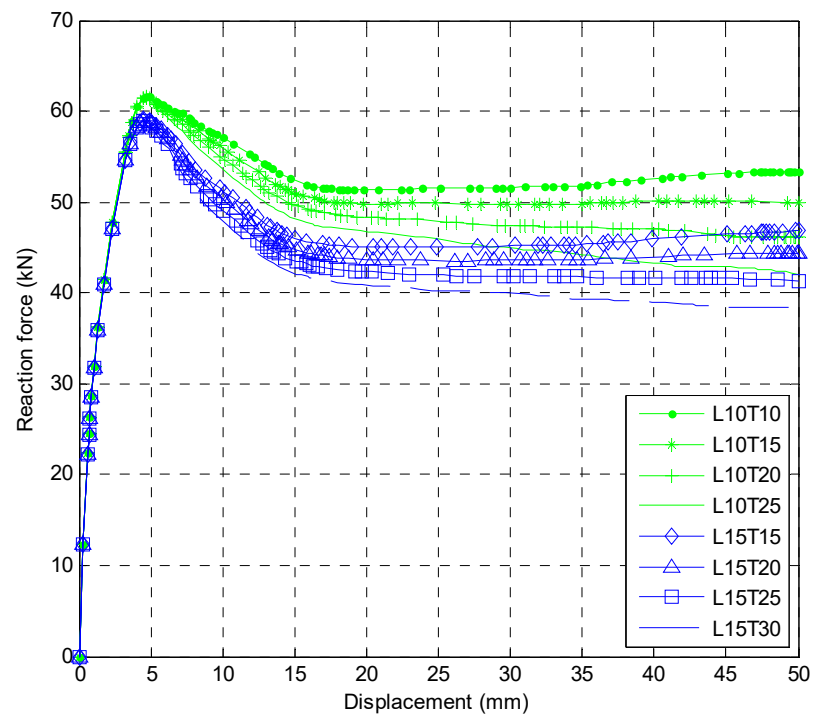

Figure 7: Pushover curves of all specimens.

\subsection{Fragility analysis based on nonlinear pushover analysis}

The fragility function describes the probability that seismic demand $D$ exceeds seismic capacity $C$ for designated limit states, and it is expressed as: 


$$
F_{c}(d)=P[D>C \mid D=d]=\Phi\left[\frac{\ln \left(d / m_{C}\right)}{\beta_{C}}\right]=\Phi\left[\frac{\ln (d)-\alpha_{C}}{\beta_{C}}\right]
$$

where $m_{C}, \alpha_{C}$ and $\beta_{C}$ are the median, logarithmic mean and logarithmic standard deviation (S.D.) of seismic capacity. Freeman et al. [14] put forward the capacity spectrum method (CSM) based on nonlinear static analysis. The capacity spectrum is established by transforming the base-shear displacement pushover curve into acceleration-displacement-response-spectrum (ADRS) format. Then the demand curve is produced based on different structural vibration periods and corresponding influence coefficients. The targeted displacement or displacement of the performance point (PP) is obtained through the comparison between the capacity spectrum and demand spectrum. According to Freeman's research contribution, official standardized fragility derivation procedures have been developed. The Federal Emergency Management Agency (FEMA) [15] has issued HAZUS 99, an applicable standard methodology which uses nonlinear pushover analysis to establish the seismic capacity curve and generate fragility functions. It is a mature and widely employed method in risk estimation of various hazards for diverse infrastructures. HAZUS 99 offers procedures for fragility analysis of a corroded RC column in this research. Limit states are categorized into slight damage, moderate damage, extensive damage and collapse according to the drift angle.

In order to investigate the fragility of circular columns with severely damaged transverse rebar, two cases were considered, L10T10 and L10T20, the fragility curves of which are shown in Fig. 8. This figure shows that L10T20 is more vulnerable to extensive damage and collapse than L10T10, although they have the same probability to have slight and moderate damage. It provides typical examples of RC structures with more severe damaged transverse rebar being at higher risk of seismic attack.

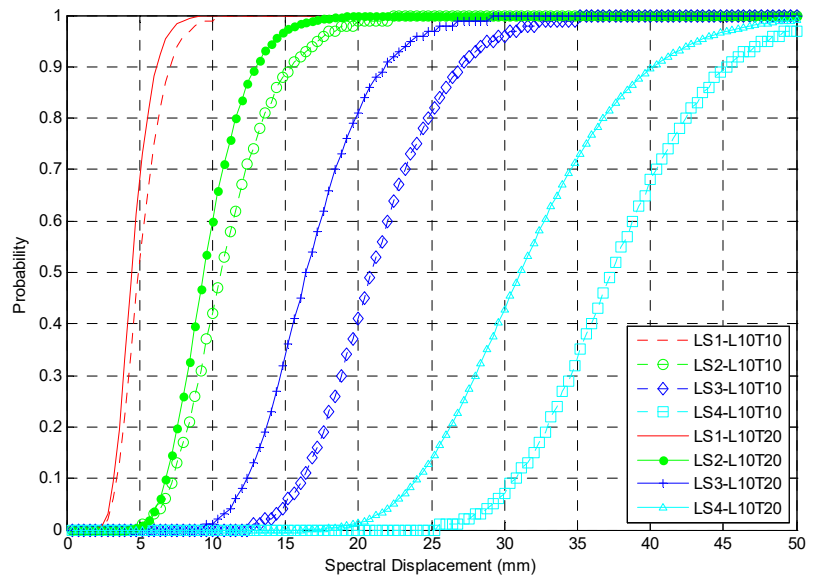

Figure 8: Fragility curves of L10T10 and L10T20. 


\section{Concluding remarks}

This paper suggests a feasible methodology of modelling corroded RC structures using software Abaqus 6.10.1. Corrosion-induced cover cracking, deteriorated rebar and the bond strength between concrete and rebar have been validly simulated with the functionalities in this software. Simulation results have shown that RC columns with severely corrosion damaged transverse rebar have lower seismic capacity, smaller seismic ductility and brittle failure modes. Transverse rebars have greater influence on the behaviour of columns when the longitudinal rebar corrosion level is below 15\%. Analysis has demonstrated that high corrosion of transverse rebars should be considered separately because of its changing power in seismic capacity and ductility. Fragility analysis has found that RC structures with higher transverse corrosion level are more vulnerable.

All the columns are tested under monotonic loading so the energy consuming ability is not analysed. This paper only presents the analysis results of columns under monotonic loading when transverse rebar has a higher corrosion level than that of a longitudinal rebar. Research should be carried out on time-variant corrosion level of transverse rebar and longitudinal rebar. A probability model should be developed to describe the corrosion level of transverse rebar as a function of longitudinal rebar corrosion level. Furthermore, further work could focus on how to model corroded columns under cyclic loading and how to generate fragility curves of corroded RC elements.

\section{References}

[1] Li, C.Q. \& Yang, S.T., Prediction of concrete crack width under combined reinforcement corrosion and applied load. Journal of Engineering Mechanics, 137(11), pp. 722-731, 2011.

[2] Ma, Y., Che, Y. \& Gong, J., Behavior of corrosion damaged circular reinforced concrete columns under cyclic loading. Construction and Building Materials, 29, pp. 548-556, 2012.

[3] Wang, X.H. \& Liang, F.Y., Performance of RC columns with partial length corrosion. Nuclear Engineering and Design, 238(12), pp. 3194-3202, 2008.

[4] Ou, Y.C., Fan, H.D. \& Nguyen, N.D., Long-term seismic performance of reinforced concrete bridges under steel reinforcement corrosion due to chloride attack. Earthquake Engineering \& Structural Dynamics, 42(14), pp. 2113-2127, 2013.

[5] Sæther, I. \& Sand, B., FEM simulations of reinforced concrete beams attacked by corrosion. Nordic Concrete Research, 39(2), 2012.

[6] Abaqus 6.10 Documentation, http://www.tu-chemnitz.de/projekt/abq_hilfe /docs/v6.10/

[7] Bazant, Z.P., Physical model for steel corrosion in concrete sea structures application. ASCE Proceedings, Journal of the Structural Division, 105(ST6), pp. 1155-1166, 1979. 
[8] Liu, T. \& Weyers, R.W., Modeling the dynamic corrosion process in chloride contaminated concrete structures. Cement and Concrete Research, 28(3), pp. 365-379, 1998.

[9] Vu, K., Stewart, M.G. \& Mullard, J., Corrosion-induced cracking: experimental data and predictive models. ACI Structural Journal, 102(5), pp. 719-726, 2005.

[10] Li, J., Gong, J. \& Wang, L., Seismic behaviour of corrosion-damaged reinforced concrete columns strengthened using combined carbon fiber-reinforced polymer and steel jacket. Construction and Building Materials, 23(7), pp. 2653-2663, 2009.

[11] Lee, H.S., Noguchi, T. \& Tomosawa, F., Evaluation of the bond properties between concrete and reinforcement as a function of the degree of reinforcement corrosion. Cement and Concrete Research, 32(8), pp. 1313-1318, 2002.

[12] Comité euro-international du béton, CEB-FIP Model Code 1990: Design Code. No. 213-214. FIB-Féd. Int. du Béton, 1993.

[13] Xu S.H., Degradation model of Reinforced Concrete Structure and Durability Assessment, Doctoral dissertation, Xi'an University of Architecture and Technology, 2003. (In Chinese).

[14] Freeman, S.A., Nicoletti, J.P. \& Tyrell, J.V., Evaluations of existing buildings for seismic risk - A case study of Puget Sound Naval Shipyard, Bremerton, Washington. Proceedings of the 1st US National Conference on Earthquake Engineering, pp. 113-122, 1975.

[15] Federal Emergency Management Agency (FEMA), National Institute of Building Sciences (NIBS), Earthquake loss estimation methodology: HAZUS 99, Washington, DC, USA, 1999. 